\title{
Topical infliximab for the suppression of wound healing following experimental glaucoma filtration surgery
}

This article was published in the following Dove Press journal:

Drug Design, Development and Therapy

2 May 2014

Number of times this article has been viewed

Burak Turgut ${ }^{\prime}$

Kenan Eren'

Mehmet Mustafa Akın²

Tamer Demir ${ }^{\prime}$

Sabiha Kobat'

'Department of Ophthalmology, School of Medicine, Fırat University, Elazı̆̆, Turkey; ${ }^{2}$ Department of Pathology, School of Medicine, Firat University, Elazığ, Turkey
Correspondence: Burak Turgut Fırat University Hospital, 23। 19, Elazı̆̆, Turkey

Tel +90 42 42333555

Fax +90 4242388096

Email drburakturgut@gmail.com
Background: The purpose of this work was to look into the effects of infliximab on wound healing in experimental glaucoma filtration surgery and to compare the antifibrotic effects of this agent to that of mitomycin-C (MMC).

Methods: Twenty-eight male New Zealand White rabbits were randomly assigned to four groups, each including seven rabbits: control group, sham group, MMC group, and infliximab group. The rabbits in the control group were not operated on and did not receive any treatment. The rabbits in the sham group underwent trabeculectomy and had one drop of saline instilled four times a day for 14 days. The rabbits in the MMC treatment group underwent trabeculectomy, and a sponge soaked in $0.4 \mathrm{mg} / \mathrm{mL}$ MMC was applied intraoperatively to the scleral surgical site for three minutes. The rabbits in the infliximab treatment group underwent trabeculectomy and one drop of $10 \mathrm{mg} / \mathrm{mL}$ infliximab was instilled four times a day for 14 days after surgery. On day 14 of the experiment, the operated and control eyes were enucleated and histologically and immunohistochemically analyzed.

Results: The mean fibroblast and mononuclear cell (MNC) numbers and the mean immunostaining intensities of transforming growth factor- $\beta$ (TGF- $\beta$ ), fibroblast growth factor- $\beta$ (FGF- $\beta$ ), and platelet-derived growth factor (PDGF) in the sham group were higher than those of the control group $(P<0.01)$. The mean fibroblast and MNC numbers and the mean immunostaining intensities of TGF- $\beta$, FGF- $\beta$, and PDGF in the MMC and infliximab groups were statistically significantly lower than those of the sham group $(P<0.01)$. The mean fibroblast and MNC numbers and the mean TGF- $\beta$, FGF- $\beta$, and PDGF immunostaining intensities of the MMC and infliximab groups were similar $(P>0.05)$.

Conclusion: Our study suggests that topical infliximab effectively suppresses the subconjunctival wound healing response after experimental glaucoma filtration surgery, reducing the $\mathrm{MNC}$ and fibroblast numbers and immunostaining intensities of TGF- $\beta$, FGF- $\beta$, and PDGF.

Keywords: mitomycin-C, trabeculectomy, anti-TNF, growth factors

\section{Introduction}

Glaucoma is a multifactorial, progressive optic neuropathy characterized by retinal ganglion cell death, the loss of visual field, and excavation of the optic nerve head. Glaucoma, the second leading cause of preventable blindness, is usually caused by the effects of elevated intraocular pressure (IOP). As elevated IOP is the only treatable risk factor for disease, the reduction of IOP is the main management method for glaucoma. Glaucoma surgery is indicated if target pressures are not achieved, or if the glaucomatous optic neuropathy progresses despite maximally tolerated medical and laser therapies. ${ }^{1}$ 
Currently, trabeculectomy is still the most reliable and most widely performed surgical procedure to lower IOP in the vast majority of patients with uncontrolled glaucoma despite maximal medical therapy. Trabeculectomy allows the drainage of aqueous humor from the anterior chamber to the subconjunctival space by creating a half-scleralthickness limbal fistula. This procedure reduces IOP by a filtering bleb. ${ }^{2-4}$ The failure of glaucoma filtration surgery (GFS) is usually due to excessive wound healing under the conjunctiva or over the scleral flap causing failure of the filtering blebs. Thus, suppression of the wound healing response is very important in preventing obstruction of the established fistula. ${ }^{5,6}$

Fibroblasts are the primary cell type to play a role in wound healing in the scleral flap region following GFS. In addition, mononuclear cells (MNCs) are well known to be the primary source of fibrogenic and angiogenic cytokines such as transforming growth factor (TGF), fibroblast growth factor (FGF), and platelet-derived growth factor (PDGF), which play an authoritative part in initiating wound healing. These growth factors cause the most potent influence on fibroblasts, and they increase the activity of fibroblasts and enhance the secretion of extracellular matrix components. ${ }^{5-7}$ Thus, the suppression of fibroblasts and MNCs in the surgical region increases the success of trabeculectomy.

Currently, there are many anti-fibrotic agents used in the suppression of wound healing after GFS. Mitomycin-C (MMC) and fluorouracil are the most used anti-fibrotic agents to increase the success of trabeculectomy. However, they have serious adverse effects such as corneal endothelial toxicity, bleb leaking, hypotonous maculopathy, blebitis, and endophthalmitis..$^{8-12}$ Thus, new agents that are more selective and less toxic are needed to suppress wound healing after GFS.

Infliximab is a mouse/human chimeric monoclonal IgG1 antibody against tumor necrosis factor (TNF)- $\alpha$. TNF- $\alpha$ is a local paracrine and autocrine regulator for low-density leukocyte and endothelial cells. It stimulates mononuclear phagocytes as well as other cell types that produce various proinflammatory cytokines and chemokines and induces migration of polymorphic nuclear leukocytes. Infliximab binds to the TNF- $\alpha$ molecule and reduces lymphocyte migration and production of proinflammatory cytokines, including interleukin (IL)-1, IL-6, and adhesion molecules. It is an agent used in the treatment of disorders such as Crohn's disease, ulcerative colitis, rheumatoid arthritis, ankylosing spondylitis, and autoimmune ocular inflammatory diseases such as uveitis, scleritis, and Behçet's disease. ${ }^{13-15}$ It was also recently reported that infliximab is effective in treating choroidal neovascularization and in the prevention of corneal neovascularization. ${ }^{16,17}$ In recent studies, it was demonstrated that infliximab downregulated expression and levels of the cytokines that play a role in the wound healing response, including TGF- $\beta$, basic FGF, and PDGF-B. ${ }^{18-20}$

To the best of our knowledge, there is no previous study in the literature on the suppression of wound healing with topical infliximab following GFS. In our study, we aimed to investigate the effects of infliximab on wound healing in experimental GFS and to compare the anti-fibrotic effects of this agent with those of MMC.

\section{Methods}

The study included 28 male New Zealand White rabbits weighing 2,500-3,000 g each. The animals were kept under appropriate dietary conditions in special cages in the experimental research center at Firat University, Elazığ, Turkey throughout the study. The animals were housed in wire-bottomed individual cages at room temperature (airconditioned, $22^{\circ} \mathrm{C}-26^{\circ} \mathrm{C}$ ) on a 12 -hour light-dark cycle. All of the rabbits were acclimatized for at least 1 week before the experiments started. The animals were fed standard rabbit chow, but were given only water 12 hours before surgery. The study was approved by the Institutional Animal Care and Use Ethics Committee of Frrat University. All experiments and the animal-related procedures were performed with strict adherence to the guidelines for animal care and experimentation by the Association for Research in Vision and Ophthalmology (ARVO) as described in their Statement for the Use of Animals in Ophthalmic and Visual Research. Only one eye of the rabbits in the study groups was subjected to standard preparation for surgery, anesthesia, and the surgical technique.

\section{Study groups}

The rabbits were randomly assigned to four groups, each including seven rabbits: control group, sham group, MMC group, and infliximab group. The rabbits in the control group were not operated on and did not receive any treatment. The rabbits in the sham group underwent trabeculectomy and had one drop of saline instilled four times a day for 14 days. The rabbits in the MMC treatment group underwent trabeculectomy, and a sponge soaked in $0.4 \mathrm{mg} / \mathrm{mL} \mathrm{MMC} \mathrm{was} \mathrm{applied} \mathrm{intraoperatively} \mathrm{to} \mathrm{the} \mathrm{scleral}$ surgical site for 3 minutes. The rabbits in the infliximab 
treatment group underwent trabeculectomy, and one drop of $10 \mathrm{mg} / \mathrm{mL}$ infliximab was instilled four times a day for 14 days after surgery.

\section{Anesthesia technique}

A combination of intramuscular $50 \mathrm{mg} / \mathrm{kg}$ ketamine hydrochloride (Ketalar; Eczacibasi Holding Co, Istanbul, Turkey) and $6 \mathrm{mg} / \mathrm{kg}$ xylazine hydrochloride (Rompun ${ }^{\circledR}$; Bayer AG, Leverkusen, Germany) was used in the anesthesia and analgesia. Before the operation, a single drop of $0.5 \%$ proparacaine hydrochloride (Alcaine; Alcon Laboratories, Inc., Fort Worth, TX, USA) was instilled in the eyes to be operated on.

\section{Surgical procedure}

The eyes of the rabbits were cleaned and draped for surgery. The surgical procedure was performed using an operating microscope (Carl Zeiss Meditec AG, Jena, Germany) A limbal-based trabeculectomy, as described by Cairns, ${ }^{21}$ was performed on the right eyes of all the rabbits in the study groups, except for the control group. Briefly, a lid speculum was placed and a partial-thickness 8-0 silk corneal traction suture was applied superiorly to pull down and fix the eyeball. A peritomy was made $5 \mathrm{~mm}$ above the limbus to form a limbus-based conjunctival flap. A limbus-based rectangular $(2.5 \times 2.5 \mathrm{~mm})$ scleral flap was outlined with a steel blade and carefully dissected. A trephine (1.5 $\mathrm{mm}$ in diameter) was then applied to make the entry into the anterior chamber at the surgical limbus, and a peripheral iridectomy was performed. The site of the peripheral iridectomy led to detection of the location of the bleb in the histopathologic examination. The scleral flap was closed by suturing with 10-0 nylon at two points, and the conjunctival wound was closed by suturing with two 9-0 polyglactin sutures.

The rabbits in the sham group received one drop of saline four times a day for 14 days after the surgery. In the MMC group, a sponge soaked in $0.4 \mathrm{mg} / \mathrm{mL}$ MMC was applied to the scleral surgical site for 3 minutes, after which the application area was thoroughly irrigated with $10 \mathrm{~mL}$ of balanced salt solution. The rabbits in the infliximab treatment group underwent trabeculectomy and one drop of $10 \mathrm{mg} / \mathrm{mL}$ infliximab was instilled four times a day for 14 days after surgery.

\section{Histopathologic preparation and assessment}

At the end of the 14th postoperative day, the eyes were enucleated, the rabbits were anaesthetized again, and the globes were enucleated together with the conjunctiva, including the bleb, for histologic examination. Single (right) eyes of the rabbits in the control group were also prepared for histologic examination. The operation site of each enucleated eye was dissected as a blockage, which contained the conjunctiva, Tenon's capsule, and sclera. The surgical area was indicated by the location of the iridectomy. After this procedure, the animals were allowed to live.

The tissue specimens were fixed in $10 \%$ formaldehyde and embedded in paraffin before the sections were cut. Serial sections ( $4 \mu \mathrm{m}$ thick) were cut, dehydrated, and stained with hematoxylin and eosin stain for light microscopy examination. The specimens were stained with Masson's trichrome, and microscopic analysis was performed using $\times 400$ objective of a standard light microscope (BX50 photomicroscope; Olympus Corporation, Tokyo, Japan). Using a specific micrometer attached to the microscope, fibroblasts and MNCs in ten randomly determined sections (area of $50 \mu \mathrm{m}^{2}$ ) were counted, and the average numbers of cells in these zones were analyzed. The values obtained from the cell counts of the ten serial sections were presented as arithmetic means and standard deviation.

\section{Immunohistochemistries of TGF- $\beta$, FGF- $\beta$, and PDGF}

Serial slides ( $4 \mu \mathrm{m}$ thick) including the bleb site were prepared. The slides were stained with TGF- $\beta$, FGF- $\beta$, and PDGF kits (Bioss Inc., Woburn, MA, USA) in an automated immunostainer device (BenchMark XT; Ventana Medical Systems, Inc., Tucson, AZ, USA) according to the manufacturer's instructions. The slides, covered with a special cover substrate, were randomly evaluated under a light microscope (Olympus BX50 photomicroscope). Digital photographs of the tissues were taken at $\times 40$ magnification using the camera on the microscope. Immunostaining intensities of TGF- $\beta$, FGF- $\beta$, and PDGF were determined semiquantitatively as none (0), weak (1), moderate (2), or intense (3).

\section{Statistical evaluation}

Statistical analysis of the study was performed with IBM SPSS Statistics software (v 21; IBM Corporation, Armonk, NY, USA) to determine the differences between the study groups. The values obtained from the cell counts of the ten serial sections were presented as arithmetic means and standard deviation. For multiple comparisons, a one-way analysis of variance test was done to analyze the fibroblast and MNC numbers among the groups. Tukey's post hoc test was used for binary comparisons among the groups. TGF- $\beta$, FGF- $\beta$, and 
PDGF immunostaining differences were assessed with the Kruskal-Wallis test. $P$-values less than 0.05 were considered statistically significant.

\section{Results}

The means and standard deviations of the fibroblast and MNC numbers in the study groups are presented in Table 1. The means and standard deviations of the TGF- $\beta$, FGF- $\beta$, and PDGF immunostaining intensities in the study groups are presented in Table 2.

The mean fibroblast and MNC numbers and the mean TGF- $\beta$, FGF- $\beta$, and PDGF immunostaining intensities of the sham group were higher than those of the control group $(P<0.01)$. The mean fibroblast and MNC numbers and the mean of TGF- $\beta$, FGF- $\beta$, and PDGF immunostaining intensities of the MMC and infliximab group were statistically significantly lower than those of the sham group $(P<0.01)$. There was no statistically significant difference between the mean MNC and fibroblast numbers and the mean immunostaining intensities of TGF- $\beta$, FGF- $\beta$, and PDGF in the MMC and infliximab groups $(P>0.05)$.

Comparative microphotographs showing fibroblast proliferation and MNC infiltration at the bleb site of each of the rabbits in the study groups are shown in Figure 1.

Microphotographs of the immunostaining of TGF- $\beta$, FGF- $\beta$, and PDGF, of one subject from each study group, are shown in Figures 2-4, respectively.

\section{Discussion}

Antimetabolites such as MMC and fluorouracil have dramatically augmented the success of GFS, especially in patients at higher risk of surgical failure due to excessive wound healing in the surgical region. However, there is a risk of blindness with antimetabolite use. ${ }^{8-12}$ Additionally, surgical failure can occur despite the use of these powerful antimetabolites. Thus, there is a need for potent agents that have no severe adverse effects.

Table I Numbers of MNCs and fibroblasts in the study groups

\begin{tabular}{lcl}
\hline Study group & $\begin{array}{l}\text { Number of MNCs } \\
\text { (mean } \pm \text { SD) }\end{array}$ & $\begin{array}{l}\text { Number of fibroblasts } \\
\text { (mean } \pm \text { SD) }\end{array}$ \\
\hline Control $(n=7)$ & $2.75 \pm 1.16$ & $2.00 \pm 0.53$ \\
Sham $(n=7)$ & $24.71 \pm 7.36^{\mathrm{a}}$ & $2.85 \pm 0.37^{\mathrm{a}}$ \\
MMC $(\mathrm{n}=7)$ & $10.42 \pm 4.27^{\mathrm{a}, \mathrm{b}}$ & $1.57 \pm 0.53^{\mathrm{b}}$ \\
Infliximab $(\mathrm{n}=7)$ & $5.25 \pm 1.28^{\mathrm{a}, \mathrm{b}}$ & $1.37 \pm 0.5 \mathrm{I}^{\mathrm{b}}$ \\
\hline
\end{tabular}

Notes: a Control group compared with sham group $(P<0.0 \mathrm{I})$; ${ }^{\text {b treatment groups }}$ compared with sham group $(P<0.0 \mathrm{I})$.

Abbreviations: MMC, mitomycin-C; MNCs, mononuclear cells; SD, standard deviation.
Fibroblasts, the main cells responsible for excessive wound healing at the scleral flap region following GFS, synthesize collagen, which is the most important component of granulation tissue. Tenon's capsule fibroblast proliferation is stimulated by epidermal growth factor, FGF, TGF- $\beta$, insulinlike growth factor-1, PDGF, fibronectin, transferrin, IL-1, and IL- 6 . TGF- $\beta$ is the most potent stimulator of fibroblast activity. ${ }^{5-7,22,23}$ Additionally, after conjunctival and scleral surgery, PDGF is released from platelets, which promotes cell migration into the wound site and increases fibroblast proliferation. ${ }^{6,7,22-26}$ Thus, the inhibition of fibroblast function after GFS is an important factor in the wound healing process and for the outcome of GFS.

In our study, fibroblast infiltration was significantly suppressed in the MMC and infliximab groups. However, there was no statistically significant difference between the MMC and infliximab groups. It is possible that infliximab inhibits fibroblast proliferation and migration by toxic effect or by reducing TGF- $\beta$, FGF- $\beta$, and PDGF, as seen in our study.

MNCs are cells coming to the surgical wound region subsequent to polymorph nuclear leukocytes. The chemotaxis of MNCs is increased with fibronectin, growth factors, and the complement system. Macrophages are MNCs derived from monocytes and they secrete various factors that stimulate migration and proliferation of the fibroblasts. They promote early wound healing and play a crucial role in tissue remodeling in the later phases of wound healing. ${ }^{5,22,27,28}$ Macrophages are thought to be the principal source of fibrogenic and angiogenic cytokines such as PDGF and TGF- $\beta .{ }^{29}$ It has been reported that the conjunctiva of patients whose GFS failed contain more macrophages. MNCs also release enzymes that augment tissue degradation, generate chemotactic factors that recruit inflammatory cells, and interact with lymphocytes. They produce cytokines and cause the accumulation and proliferation of fibroblasts and endothelial cells, with subsequent

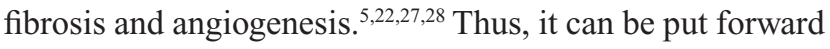
that a decreased number of macrophages parallels a suppressed wound healing reaction and surgical success. In our study, MNC infiltration in the bleb region was significantly suppressed in the MMC and infliximab groups; however, the differences between these two groups were not statistically significant. The reduction in the number of MNCs in both treatment groups was presumably the effect of decreased growth factor levels.

TGF- $\beta$ is produced by macrophages, lymphocytes, platelets, and fibroblasts, and it is one of the most important profibrogenic cytokines in the conjunctival wound healing process, causing the proliferation and migration of human 
Table 2 TGF- $\beta$, FGF- $\beta$, and PDGF immunostaining intensities in the study groups

\begin{tabular}{llll}
\hline Study group & $\begin{array}{l}\text { TGF- } \beta \text { immunostaining } \\
\text { intensity (mean } \pm \text { SD) }\end{array}$ & $\begin{array}{l}\text { FGF- } \beta \text { immunostaining } \\
\text { intensity (mean } \pm \text { SD) }\end{array}$ & $\begin{array}{l}\text { PDGF immunostaining } \\
\text { intensity (mean } \pm \text { SD) }\end{array}$ \\
\hline Control $(n=7)$ & $1.87 \pm 0.35$ & $1.87 \pm 0.35$ & $1.50 \pm 0.53$ \\
Sham $(n=7)$ & $2.85 \pm 0.37^{\mathrm{a}}$ & $3.00 \pm 0.0^{\mathrm{a}}$ & $2.85 \pm 0.37^{\mathrm{a}}$ \\
MMC $(\mathrm{n}=7)$ & $1.42 \pm 0.53^{\mathrm{b}}$ & $1.57 \pm 0.53^{\mathrm{b}}$ & $1.71 \pm 0.53^{\mathrm{b}}$ \\
Infliximab $(\mathrm{n}=7)$ & $1.37 \pm 0.5 \mathrm{I}^{\mathrm{b}}$ & $1.37 \pm 0.5 \mathrm{I}^{\mathrm{b}}$ & $1.50 \pm 0.5 \mathrm{I}^{\mathrm{b}}$ \\
\hline
\end{tabular}

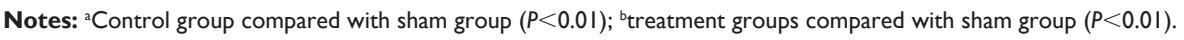

Abbreviations: FGF- $\beta$, fibroblast growth factor beta; PDGF, platelet-derived growth factor; SD, standard deviation; TGF- $\beta$, transforming growth factor beta; MMC, mitomycin-C.

Tenon's fibroblasts and promoting collagen production. ${ }^{23,30-34}$ TGF- $\beta$ and PDGF have the strongest influence on wound healing, as these growth factors increase fibroblast activity. ${ }^{35,36}$ Reduced levels of TGF- $\beta$ have been correlated with the retardation of the wound healing process in burn injury and with non-scarring fetal skin repair. ${ }^{37,38}$ Similarly, decreased levels of PDGF have been observed in non-healing wounds in diabetic rats. ${ }^{38}$ On the other hand, elevated levels of TGF- $\beta$ are associated with increased fibrosis in several organs, including the heart, liver, kidney, lung, skin, and bone marrow. ${ }^{39-42}$ TGF- $\beta$ is considered to inhibit the growth of leukocytes and to stimulate the production of fibroblasts. ${ }^{43,44}$ TGF- $\beta$ enhances resistance of the wound site to tension in corneal incisions in rabbits by enhancing the number of fibroblasts through chemotaxis, reducing the synthesis of matrix metalloprotease, and enhancing the synthesis of metalloprotease tissue inhibitor. ${ }^{42}$ In mouse models of conjunctival scarring, it has been reported that TGF- $\beta 2$ applied to mouse conjunctiva following MMC application significantly reversed the antiscarring effects of MMC. ${ }^{31,32}$ Inhibiting TGF- $\beta$ might be an
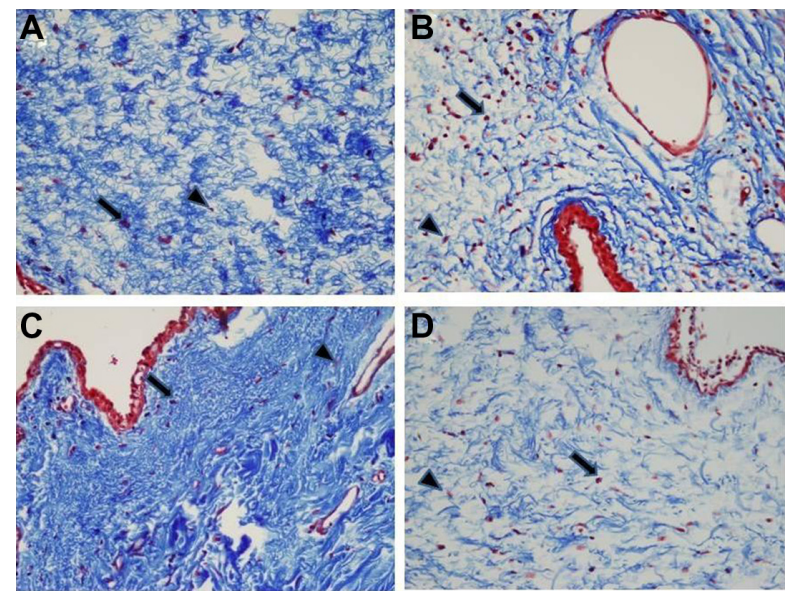

Figure I Microphotographs of the bleb site of one rabbit from each of the sham and treatment groups.

Notes: Control (A), sham (B), mitomycin-C (C), and infliximab (D) groups. Arrowheads indicate fibroblasts while arrows indicate mononuclear cells. (B) shows numerous fibroblasts and mononuclear cells. (C and $\mathbf{D})$ show a significant decrease in the number of fibroblasts and mononuclear cells. Masson's trichrome was used for staining. Original magnification $\times 400$. effective means of preventing postoperative scarring after trabeculectomy. In our study, MMC and infliximab similarly reduced the immunostaining density of TGF- $\beta$ at the scleral flap region. Although the exact mechanisms underlying this response are not known, it might be that exposure to $\mathrm{MMC}$ reduces human Tenon's fibroblasts, which are one of the main producers of TGF- $\beta$.

FGF- $\beta$ secreted by macrophages and endothelial cells stimulates fibroblast migration and proliferation. Tenon's capsule fibroblasts exposed to MMC have been reported to exhibit a significant decrease in the number of FGF- $\beta$ receptors. ${ }^{40-44}$ In our study, MMC and infliximab equally decreased the immunostaining intensity of FGF- $\beta$ in the bleb region. As both drugs strongly suppressed fibroblast proliferation and reduced FGF- $\beta$, the use of both drugs together would be considered.

PDGF also plays a very important role in wound healing by promoting the proliferation and migration of fibroblasts. ${ }^{40-44}$ Studies by Denk et al strongly support the hypothesis that PDGF isoforms are major stimulators

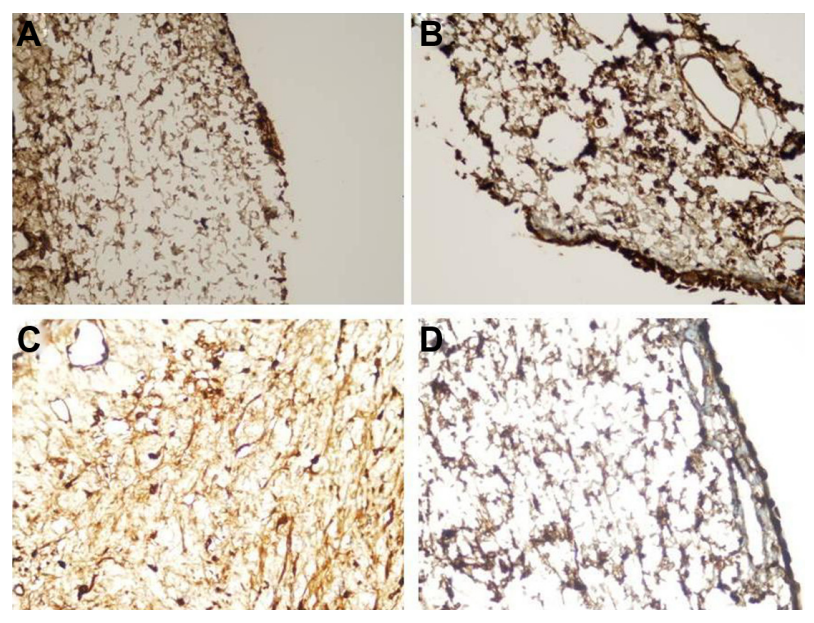

Figure 2 Immunohistochemistry microphotographs showing the intensities of transforming growth factor- $\beta$ immunostaining of one rabbit from each of the sham and treatment groups.

Notes: Control (A), sham (B), mitomycin-C (C), and infliximab (D) groups. Dense staining can be seen in (B). (C and $\mathbf{D})$ show decreased transforming growth factor- $\beta$ immunostaining. 


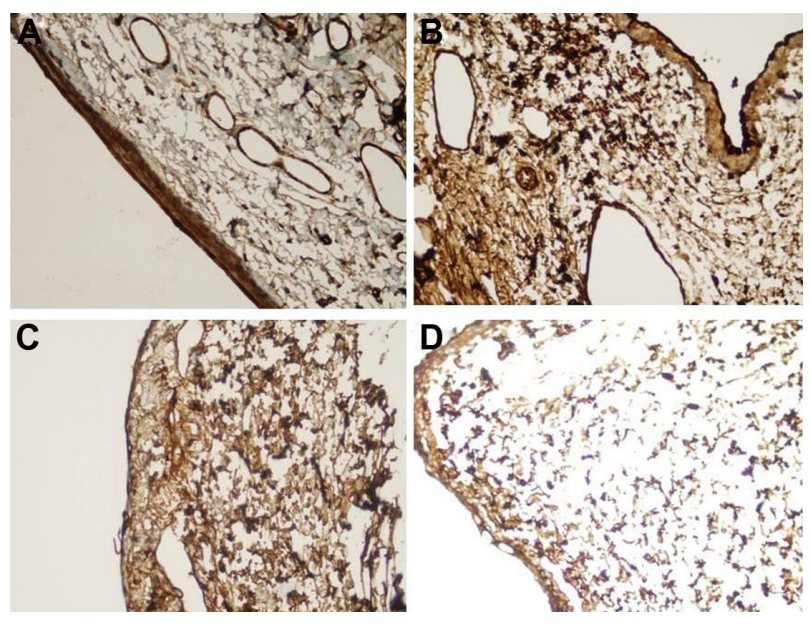

Figure 3 Immunohistochemistry microphotographs showing the intensities of fibroblast growth factor- $\beta$ immunostaining of one rabbit from each of the sham and treatment groups.

Notes: Control (A), sham (B), mitomycin-C (C), and infliximab (D) groups. Dense staining can be seen in (B). (C and D) show decreased fibroblast growth factor- $\beta$ immunostaining.

of proliferation of Tenon's capsule fibroblasts after GFS, while TGF- $\beta$ isoforms are essential for the transformation of Tenon's capsule fibroblasts into myofibroblasts. ${ }^{25,44}$ In another study, Knorr et al demonstrated that PDGF-AB and -BB isoforms are potent stimulators of the proliferation of human Tenon's capsule fibroblasts, suggesting that they play an important role in the wound healing response after GFS. ${ }^{26}$ PDGF is normally present in trace amounts in the aqueous humor and increases the proliferative response of fibroblasts to TGF- $\beta .{ }^{44}$ PDGF is also a chemoattractant for trabecular meshwork cells. In turn, TGF- $\beta$ regulates tissue

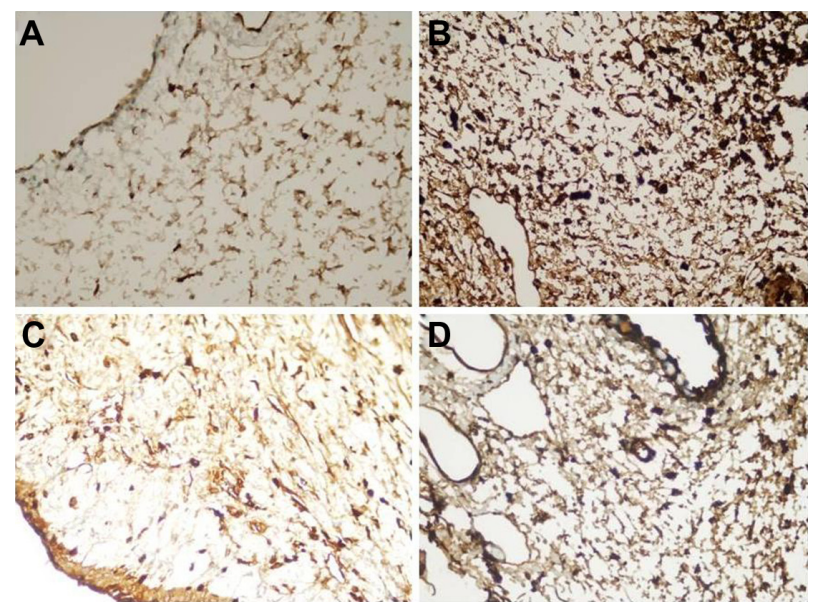

Figure 4 Immunohistochemistry microphotographs showing the intensities of platelet-derived growth factor immunostaining of one rabbit from each of the sham and treatment groups.

Notes: Control (A), sham (B), mitomycin-C (C), and infliximab (D) groups. Dense staining can be seen in (B). (C and $\mathbf{D})$ show decreased platelet-derived growth factor immunostaining. growth through PDGF protein and receptor expression in keratocytes, although the exact mechanism by which this takes place is unknown. In other connective tissues, low TGF- $\beta$ concentrations promote PDGF production, whereas, at high TGF- $\beta$ concentrations, the PDGF receptor expression is decreased..$^{40-45}$ In our study, MMC and infliximab equally decreased the immunostaining intensity of PDGF in the scleral flap region. This finding is compatible with the fibroblast-reducing effect of both drugs.

MMC is an antimetabolite and antitumor agent that is isolated from Streptomyces caespitosus and which decreases fibroblast proliferation in both the subconjunctival space and Tenon's capsule. It is widely used in trabeculectomy to prevent excessive postoperative wound healing in the surgical site in cases at risk of surgical failure, due to its anti-fibrotic and anti-scarring properties. Yamamoto et al reported that MMC inhibited the proliferation and motility of cultured rabbit subconjunctival fibroblasts and that its inhibitor effect depends on dose and time of exposure to the drug. ${ }^{46}$ Another experimental study demonstrated that histologic examination of eyes with MMC-treated trabeculectomy revealed hypocellular and well-formed bleb cavities, and that a single intraoperative application of MMC had a marked effect on postoperative wound healing after filtration surgery in monkeys. ${ }^{47}$ However, topically applied MMC has severe ocular complications, such as necrosis in the cornea and conjunctiva, scleral perforation, choroidal detachment, epithelial downgrowth, filtration bleb failure, and endophthalmitis. ${ }^{10-13}$ Although MMC is widely used in GFS with high success rates, it is not possible to use it in every case that has a high risk of failure. In addition, MMC is one of the ten most carcinogenic substances to humans. ${ }^{48}$

Infliximab is a human murine monoclonal antibody that can bind to both soluble and transmembranous forms of TNF- $\alpha$ with high affinity. TNF- $\alpha$ is a local paracrine and autocrine regulator for small-density leukocyte and endothelial cells. It stimulates mononuclear phagocytes as well as other cell types that produce IL-1, IL-6, and chemokines, and induces migration of polymorphic nuclear leukocytes. TNF- $\alpha$ has a synergistic effect with IL-6 and plays a crucial role in the development of inflammation in uveitis. Furthermore, it contributes to the pathogenesis of uveoretinitis associated with Behçet's disease. ${ }^{14,15}$

Currently, there is increasing evidence that TNF- $\alpha$ is important in the initiation and perpetuation of the fibrotic process. ${ }^{49-54}$ In a recent study, Sullivan et al demonstrated that TNF- $\alpha$ induces TGF- $\beta 1$ expression in lung fibroblasts. ${ }^{49}$ Battegay et al reported that TNF- $\alpha$ stimulates DNA synthesis 
and proliferation of cultured human fibroblasts and that there is a strong relationship between secretion of PDGF and TNF- $\alpha$ stimulation. ${ }^{50}$ Therefore, we postulate that TNF- $\alpha$ may play a significant role in regulating the expression of the cytokines that themselves play an important role in wound healing after GFS, such as TGF- $\beta$, FGF, and PDGF.

Recently, infliximab has been used as a novel immunomodulatory agent, particularly in uveitis refractory to treatment, panuveitis associated with Behçet's disease, rheumatoid arthritis, and Crohn's disease. ${ }^{55}$ Infliximab was shown to inhibit the functional activity of TNF- $\alpha$ in several in vitro studies. ${ }^{56,57}$ It has been suggested that infliximab exerts its clinical effects in patients with uveitis through various mechanisms, which include reducing serum levels of inflammatory mediators by blocking TNF- $\alpha$, preventing lymphocyte migration, and decreasing levels of vascular endothelial growth factor. ${ }^{58}$ Binding of infliximab to soluble TNF- $\alpha$ brings about a decrease in bioactivity, while its binding to membrane-bound TNF- $\alpha$ results in cytotoxicity through complement-dependent or antibody-dependent cellmediated mechanisms. Nevertheless, it is not known how infliximab acts in in vivo models. Secondary to the suppression of TNF- $\alpha$, infliximab lowers serum levels of inflammatory mediators, including IL- 1 and IL- 6 and vascular growth factors. In addition, it reduces lymphocyte migration. ${ }^{59}$

In our study, we observed that topically administered $10 \mathrm{mg} / \mathrm{mL}$ infliximab following GFS significantly suppressed fibroblast proliferation and MNC infiltration compared to the sham group, and that it was as effective and strong as MMC. It was also observed that the TGF- $\beta$, FGF- $\beta$, and PDGF immunostaining intensities of the infliximab group were significantly lower than those of the sham group. It is possible that infliximab acts via the inhibition of fibroblast proliferation and migration by toxic effect or by reducing TGF- $\beta$, FGF- $\beta$, and PDGF, as seen in our study.

As far as we know, following a search of the PubMed database, there is no previous study concerning the use of infliximab in an experimental GFS model. We consider that infliximab might reduce fibroblast infiltration via the induction of fibroblast apoptosis or suppression of the effects of TGF- $\beta$, FGF- $\beta$, and PDGF, as seen in the present study. The suppressive effect of infliximab on the number of MNCs might be related to its cycle arrest effect, apoptosis, or the inhibition of MNC chemotaxis via suppression of the effects of the abovementioned cytokines. The small number of experimental animals used can be regarded as a main limitation of our study. In this study, we used a previously reported experimental dosage and administration rate of infliximab. ${ }^{16,59}$
We did not observe any corneal or conjunctival toxicity in the histologic sections.

\section{Conclusion}

Taking into consideration the toxic effects of MMC in GFS and the strongly anti-fibroblastic effects of infliximab as well as MMC on conjunctival wound healing, infliximab can be considered a potential alternative agent for the modulation of wound healing after GFS. However, further in vivo and in vitro studies are needed to evaluate its use with GFS.

\section{Acknowledgments}

This work was funded by an unrestricted grant from Frrat University Scientific Research Unit (authors' owner institution). The study was approved by the Institutional Animal Care and Use Ethics Committee of Frrat University. All experiments and the animal-related procedures were performed with strict adherence to the guidelines for animal care and experimentation by the Association for Research in Vision and Ophthalmology (ARVO) as described in their Statement for the Use of Animals in Ophthalmic and Visual Research.

\section{Author contributions}

Involved in the conduct of the study: BT, KE, MMA, TD, SK. Collection of data, typing and editing of the manuscript, and statistical analysis: BT, KE, MMA, TD, SK. Preparation, translating, review, and approval of the final manuscript: BT, KE, MMA, TD, SK.

\section{Disclosure}

The authors report no conflicts of interest in this work.

\section{References}

1. Quigley HA. Glaucoma: macrocosm to microcosm the Friedenwald lecture. Invest Ophthalmol Vis Sci. 2005;46:2662-2670.

2. Cynthia Mattox. Trabeculectomy. In: Yanoff M, Duker JS, editors. Ophthalmology, 3rd edition. St Louis, MO, USA: Mosby; 2008: Chapter 10.30.

3. Coleman AL. Advances in glaucoma treatment and management: surgery. Invest Ophthalmol Vis Sci. 2012;53:2491-2494.

4. Salim S. Current variations of glaucoma filtration surgery. Curr Opin Ophthalmol. 2012;23:89-95.

5. Jampel HD, McGuigan LJ, Dunkelberger GR, L’Hernault NL, Quigley HA. Cellular proliferation after experimental glaucoma filtration surgery. Arch Ophthalmol. 1988;106:89-94.

6. Khaw PT, Occleston NL, Schultz G, Grierson I, Sherwood MB, Larkin G. Activation and suppression of fibroblast function. Eye (Lond). 1994;8:188-195.

7. Seibold LK, Sherwood MB, Kahook MY. Wound modulation after filtration surgery. Surv Ophthalmol. 2012;57:530-550.

8. Yoon PS, Singh K. Update on antifibrotic use in glaucoma surgery, including use in trabeculectomy and glaucoma drainage implants and combined cataract and glaucoma surgery. Curr Opin Ophthalmol. 2004; 15:141-146. 
9. Lee DA, Lee TC, Cortes AE, Kitada S. Effects of mithramycin, mitomycin, daunorubicin, and bleomycin on human subconjunctival fibroblast attachment and proliferation. Invest Ophthalmol Vis Sci. 1990;31:2136-2144.

10. Chen CW, Huang HT, Bair JS, Lee CC. Trabeculectomy with simultaneous topical application of Mitomycin C in refractory glaucoma. J Ocul Pharmacol. 1990;6:175-182.

11. Greenfield DS, Suñer IJ, Miller MP, Kangas TA, Palmberg PF, Flynn HW Jr. Endophthalmitis after filtering surgery with mitomycin. Arch Ophthalmol. 1996;114:943-949.

12. Higginbotham EJ, Stevens RK, Musch DC, et al. Blebrelated endophthalmitis after trabeculectomy with mitomycin C. Ophthalmology. 1996;103:650-656.

13. Ebert EC. Infliximab and the TNF-alpha system. Am J Physiol Gastrointest Liver Physiol. 2009;296:612-620.

14. Hosseini H, Safaei A, Khalili MR, et al. Intravitreal infliximab in experimental endotoxin-induced uveitis. Eur J Ophthalmol. 2009; 19:818-823.

15. Demir T, Gödekmerdan A, Balbaba M, Türkçüoglu P, Ilhan F, Demir N. The effect of infliximab, cyclosporine A and recombinant IL-10 on vitreous cytokine levels in experimental autoimmune uveitis. Indian $J$ Ophthalmol. 2006;54:241-245.

16. Kim JW, Chung SK. The effect of topical infliximab on corneal neovascularization in rabbits. Cornea. 2013;32:185-190.

17. Regatieri CV, Dreyfuss JL, Melo GB, Lavinsky D, Farah ME, Nader HB. Dual role of intravitreous infliximab in experimental choroidal neovascularization: effect on the expression of sulfated glycosaminoglycans. Invest Ophthalmol Vis Sci. 2009;50:5487-5494.

18. Staroslawska E, Czarnocki KJ, Koziol-Montewka M, Donica H, Magrys A. Effect of infliximab on the levels of TNF-alpha and TGF-beta in the whole blood cultures of irradiated patients. Folia Histochem Cytobiol. 2008;46:291-297.

19. Di Sabatino A, Ciccocioppo R, Benazzato L, Sturniolo GC, Corazza GR. Infliximab downregulates basic fibroblast growth factor and vascular endothelial growth factor in Crohn's disease patients. Aliment Pharmacol Ther. 2004;19:1019-1024.

20. Wollin M, Abele S, Bruns H, et al. Inhibition of TNF-alpha reduces transplant arteriosclerosis in a murine aortic transplant model. Transpl Int. 2009;22:342-349.

21. Cairns JE. Trabeculectomy. Preliminary report of a new method. Am J Ophthalmol. 1968;66:673-679.

22. Schultz G, Khaw PT, Oxford K, MaCauley S, Van Setten G, Chegini N. Growth factors and ocular wound healing. Eye (Lond). 1994;8:184-187.

23. Chang L, Crowston JG, Cordeiro MF, Akbar AN, Khaw PT. The role of the immune system in conjunctival wound healing after glaucoma surgery. Surv Ophthalmol. 2000;45:49-68.

24. Saika S, Yamanaka O, Baba Y, et al. Accumulation of latent transforming growth factor-beta binding protein-1 and TGF beta 1 in extracellular matrix of filtering bleb and of cultured human subconjunctival fibroblasts. Graefes Arch Clin Exp Ophthalmol. 2001;239: 234-241.

25. Denk PO, Roth-Eichhorn S, Gressner AM, Knorr M. Effect of cytokines on regulation of the production of transforming growth factor beta-1 cultured human Tenon's capsule fibroblasts. Eur J Ophthalmol. 2000; $10: 110-115$.

26. Knorr M, Volker M, Denk PO, Wunderlich K, Thiel HJ. Proliferative response of cultured human Tenon's capsule fibroblasts to plateletderived growth factor isoforms. Graefes Arch Clin Exp Ophthalmol. 1997;235:667-671.

27. Leibovich SJ, Wiseman DM. Macrophages, wound repair and angiogenesis. Prog Clin Biol Res. 1988;266:131-145.

28. Hawker MJ, Broadway DC. Preoperative Conjunctival Health and Trabeculectomy Outcome. In: Shaarawy T, Sherwood MB, Hitchings RA, Crowston JG, editors. Glaucoma: Surgical Management, 2nd edition. London, UK: Saunders; 2009; Chapter 68:87-94.
29. Occleston NL, Daniels JT, Tarnuzzer RW, et al. Single exposures to antiproliferatives: long-term effects on ocular fibroblast wound-healing behavior. Invest Ophthalmol Vis Sci. 1997;38:1998-2007.

30. Imanishi J, Kamiyama K, Iguchi I, Kita M, Sotozono C, Kinoshita S. Growth factors: importance in wound healing and maintenance of transparency of the cornea. Prog Retin Eye Res. 2000;19:113-129.

31. Cordeiro MF, Gay JA, Khaw PT. Human anti-transforming growth factor-beta2 antibody: a new glaucoma anti-scarring agent. Invest Ophthalmol Vis Sci. 1999;40:2225-2234.

32. Cordeiro MF, Reichel MB, Gay JA, D'Esposita F, Alexander RA, Khaw PT. Transforming growth factor-beta1, -beta2, and -beta3 in vivo: effects on normal and mitomycin C-modulated conjunctival scarring. Invest Ophthalmol Vis Sci. 1999;40:1975-1982.

33. Thomas DW, O'Neill ID, Harding KG, Shepherd JP. Cutaneous wound healing: a current perspective. J Oral Maxillofac Surg. 1995;53:442-447.

34. Pejnović N, Lilić D, Zunić G, Colić M, Kataranovski M, Dujić A. Aberrant levels of cytokines within the healing wound after burn injury. Arch Surg. 1995;130:999-1006.

35. Sullivan KM, Lorenz HP, Meuli M, Lin RY, Adzick NS. A model of scarless human fetal wound repair is deficient in transforming growth factor beta. J Pediatr Surg. 1995;30:198-203.

36. Doxey DL, Ng MC, Dill RE, Iacopino AM. Platelet-derived growth factor levels in wounds of diabetic rats. Life Sci. 1995;57:1111-1123.

37. Border WA, Noble NA. Transforming growth factor beta in tissue fibrosis. N Engl J Med. 1994;331:1286-1292.

38. Shah M, Foreman DM, Ferguson MW. Control of scarring in adult wounds by neutralising antibody to transforming growth factor beta. Lancet. 1992;339:213-214.

39. Honma Y, Nishida K, Sotozono C, Kinoshita S. Effect of transforming growth factor-beta 1 and -beta 2 on in vitro rabbit corneal epithelial cell proliferation promoted by epidermal growth factor, keratinocyte growth factor, or hepatocyte growth factor. Exp Eye Res. 1997;65:391-396.

40. Wilson SE, Schultz GS, Chegini N, Weng J, He YG. Epidermal growth factor, transforming growth factor alpha, transforming growth factor beta, acidic fibroblast growth factor, basic fibroblast growth factor, and interleukin-1 proteins in the cornea. Exp Eye Res. 1994;59:63-71.

41. Heldin CH, Westermark B. Mechanism of action and in vivo role of platelet-derived growth factor. Physiol Rev. 1999;79:1283-1316.

42. Betsholtz C, Karlsson L, Lindahl P. Developmental roles of plateletderived growth factors. Bio Essays. 2001;23:494-507.

43. Werner S, Grose R. Regulation of wound healing by growth factors and cytokines. Physiol Rev. 2002;83:835-870.

44. Denk PO, Hoppe J, Hoppe V, Knorr M. Effect of growth factors on the activation of human Tenon's capsule fibroblasts. Curr Eye Res. 2003;27:35-44.

45. Jester JV, Huang J, Petroll WM, Cavanagh HD. TGFbeta induced myofibroblast differentiation of rabbit keratocytes requires synergistic TGFbeta, PDGF and integrin signaling. Exp Eye Res. 2002;75:645-657.

46. Yamamoto T, Varani J, Soong HK, Lichter PR. Effects of 5-fluorouracil and mitomycin $\mathrm{C}$ on cultured rabbit subconjunctival fibroblasts. Ophthalmology. 1990;97:1204-1210.

47. Pasquale LR, Thibault D, Dorman-Pease ME, Quigley HA, Jampel HD. Effect of topical mitomycin-C on glaucoma filtration surgery in monkeys. Ophthalmology. 1992;99:14-18.

48. Yodaiken RE, Bennett D. OSHA work-practice guidelines for personnel dealing with cytotoxic (antineoplastic) drugs. Occupational Safety and Health Administration. Am J Hosp Pharm. 1986;43:1193-1204.

49. Sullivan DE, Ferris M, Nguyen H, Abboud E, Brody AR. TNF-alpha induces TGF-beta1 expression in lung fibroblasts at the transcriptional level via AP-1 activation. $J$ Cell Mol Med. 2009;13(8B): 1866-1876.

50. Battegay EJ, Raines EW, Colbert T, Ross R. TNF-alpha stimulation of fibroblast proliferation. Dependence on platelet-derived growth factor (PDGF) secretion and alteration of PDGF receptor expression. $J$ Immunol. 1995;154:6040-6047. 
51. Verrecchia F, Mauviel A. TGF-beta and TNF-alpha: antagonistic cytokines controlling type I collagen gene expression. Cell Signal. 2004; 16:873-880.

52. Fujita M, Shannon JM, Morikawa O, Gauldie J, Hara N, Mason RJ. Overexpression of tumor necrosis factor-alpha diminishes pulmonary fibrosis induced by bleomycin or transforming growth factor-beta. Am J Respir Cell Mol Biol. 2003;29:669-676.

53. Oikonomou N, Harokopos V, Zalevsky J, et al . Soluble TNF mediates the transition from pulmonary inflammation to fibrosis. PLoS One. 2006;1:e108.

54. Sullivan DE, Ferris M, Pociask D, Brody AR. The latent form of TGF-beta(1) is induced by TNFalpha through an ERK specific pathway and is activated by asbestos-derived reactive oxygen species in vitro and in vivo. J Immunotoxicol. 2008;5:145-149.

55. de Boer JH, van Haren MA, de Vries-Knoppert WA, et al. Analysis of IL-6 levels in human vitreous fluid obtained from uveitis patients, patients with proliferative intraocular disorders and eye bank eyes. Curr Eye Res. 1992;11 Suppl:181-186.
56. Murphy CC, Ayliffe WH, Booth A, Makanjuola D, Andrews PA, Jayne D Tumor necrosis factor alpha blockade with infliximab for refractory uveitis and scleritis. Ophthalmology. 2004;111:352-356.

57. Sfikakis PP, Theodossiadis PG, Katsiari CG, Kaklamanis P, Markomichelakis NN. Effect of infliximab on sight-threatening panuveitis in Behçet's disease. Lancet. 2001;35:295-296.

58. Remicade IV injection [prescribing information]. Malvern, PA: Centocor; 1999.

59. Ferrari G, Bignami F, Giacomini C, Franchini S, Rama P. Safety and efficacy of topical infliximab in a mouse model of ocular surface scarring. Invest Ophthalmol Vis Sci. 2013;54:1680-1688.

\section{Publish your work in this journal}

Drug Design, Development and Therapy is an international, peerreviewed open-access journal that spans the spectrum of drug design and development through to clinical applications. Clinical outcomes, patient safety, and programs for the development and effective, safe, and sustained use of medicines are a feature of the journal, which has also been accepted for indexing on PubMed Central. The manuscript management system is completely online and includes a very quick and fair peer-review system, which is all easy to use. Visit http://www.dovepress.com/testimonials.php to read real quotes from published authors.

Submit your manuscript here: http://www.dovepress.com/drug-design-development-and-therapy-journal 